\title{
Participant observation approach to study refugees' information practices
}

\author{
Khadijah Saeed Khan \\ Åbo Akademi University \\ khadijah.khan@abo.fi \\ https://orcid.org/0000-0003-1972-9806
}

\section{Introduction}

Scholarly studies of refugees and other vulnerable population carry special ethical concerns (Smith, 2009). This abstract is about the participant observation approach, which was used in a study exploring the information practices of women refugees in Sweden.

The abstract highlights the methodology and its difficulties in research with refugee women. An ethnographic approach of participant observation This article is licensed under the terms of the CC BY-NC-SA 4.0 -license 
and semi-structured interviews were conducted with 18 refugee women from different Arab countries (i.e. Iraq, Palestine, Syria) in the study. This abstract specifically introduces how participant observation method was used to collect the data in refugees' field. Ethnography is a data collection approach to get a holistic view of cultural experience of a person living within that culture and participant observation is a tool in the kit of ethnography (Kawulich, 2005). Participant observation is a primary method to get to know the field and this process enables a researcher to learn about the activities of the people under study in a natural setting through observing and participating in those activities (Kawulich, 2005). Participant observation helps to understand the 'backstage culture' and allows for richly detailed descriptions of situations and events (Lopez-Dicastillo and Belintxon, 2014). However, there are limitations with this approach such as, relying on the informants' views rather than the public views and researcher's individual interest in a setting rather than being representative of what actually happens in a culture (Uldam and McCurdy, 2013). Moreover, there are many challenges associated with this approach such as, the role of researcher as an outsider or insider, ethical issues of privacy, getting complete informed consent, trust, access and subjectivity (Li, 2008).

\section{Participant observation in a study of women refugees' information practices}

In this study, the researcher has participated in two main cultural events i.e. the day of Eid-ul-Fitar and the dinner of 27th of Ramadan to observe the women's behavior, activities and cultural settings. The participant observation took place at participants' home, community hall, during shopping and city tours and during coffee and lunch meetings by involving in informal discussions.

The researcher has taken the field notes of different activities during the events and also noted down the information needs and information challenges mentioned during the informal meetings and discussions with women. To get into the field, to get the informed consent and to interact with women was not a challenge because of the sameness advantage, in which the researcher has a benefit of having the same cultural background as the study subjects. However, due to the privacy reasons, the researcher could not record the events in any audio or video form, but had to rely on her memory to note down the observations and conversations manually in a field diary after the events. The second main limitation was the language barrier. The main language used in most of the conversations within the women was Arabic and the researcher had 
limited knowledge of basic Arabic. For this purpose, the researcher needed help from an Arab woman translator, who works as an official translator for the Red Cross organization. Even though, the translator was a close friend of most of the women at the events, she could not translate all of the conversations in the events because the nature of the events was very causal. The second main language, used in the events, was English, as there were non-Arab women attending the events. The researcher was able to understand the cultural activities and communications with most of the women involved in the research.

It is important to consider the ethical issues in dealing with vulnerable groups of people, such as refugee women. In this study, the researcher has got permission from the community cultural event organizer and from the subjects before participating in the events and she was open about her research plan to others. It was clear that the participants' behaviors were natural - even after knowing her position - in most of the situations. Moreover, the researcher has also considered possible ethical issues during the observation. For example, the heard stories of troubled lives of refugees, which appeared during the conversations in the events are not contextualized in the findings and are kept secret. The original names of the participants are also anonymized. The participants were completely volunteer in sharing their stories and involving the researcher into other activities during the events. Researcher's approach was unbiased and with due respect to the subjects' privacy, confidentiality and limits. However, it is hard for a researcher to draw lines in between the role as a researcher or as a friend of the study subjects.

The observations have provided a better understanding of the Arab culture, its meaning for women refugees and how they construct everyday life around these cultural events. Most importantly, the observation method has helped to get knowledge about the relationship between women's information practices and the Arab culture.

\section{References}

Kawulich, B. B. (2005). Participant observation as a data collection method. Forum: Qualitative social research, 6(2). http://dx.doi.org/10.17169/fqs-6.2.466

Li, J. (2008). Ethical challenges in participant observation: A reflection on ethnographic fieldwork. The Qualitative Report, 13(1), 100-115. Retrieved from https://nsuworks.nova.edu/ tqr/vol13/iss1/8

Lopez-Dicastillo, O., \& Belintxon, M. (2014). The challenges of participant observations of cultural encounters within an ethnographic study. Procedia - Social and Behavioral Sciences, 132, 522-526. https://doi.org/10.1016/j.sbspro.2014.04.347 
Smith, V. J. (2009). Ethical and effective ethnographic research methods: A case study with Afghan refugees in California. Journal of Empirical Research on Human Research Ethics, 4(3), 59-72. https://doi.org/10.1525/jer.2009.4.3.59

Uldam, J., \& McCurdy, P. (2013). Studying social movements: Challenges and opportunities for participant observation. Sociology Compass, 7(11), 941-951. https://doi.org/10.1111/ soc4.12081 